\title{
DIREITOS FUNDAMENTAIS SOCIAIS: SUA EFETIVIDADE AMPARADA PELA CONSTITUIÇÃO FEDERAL/88 NA APLICAÇÃO DE POLÍTICAS PÚBLICAS.
}

\author{
Gabriella Souza Estrogueia de Oliveira, Guilherme Samuel Augusto Oliva, Renata Poloni Sanches \\ Universidade do Oeste Paulista - UNOESTE, Curso de Direito,Presidente Prudente/SP. E-mail: gabi.seo@hotmail.com
}

\section{RESUMO}

Com a previsão dos direitos e garantias, nos quais hoje são conferidos a cada indivíduo, em especial os direitos fundamentais sociais, efetivados pela Constituição Federal/88, o presente artigo concerne em abranger de maneira simplificada a historicidade e a evolução das relações humanas, fatos que possibilitaram a ocorrência e o alcance do progresso social ao decorrer dos anos, incluindo-os na aplicação de políticas públicas no Brasil. Apresentando porém, os reflexos positivos dos projetos sociais atualmente existentes, não como uma forma de manipulação na relação entre governo e individuo, mas sim, como uma prestação obrigatória por parte do Estado Democrático de Direito. Por fim, será apresentada de modo geral uma construção social sob a primazia de uma vida digna, justa e igualitária.

Palavras-chave:Democracia, dignidade humana, progresso social, direitos fundamentais, politicas publicas.

\section{FUNDAMENTAL SOCIAL RIGHTS: IT'S EFFECTIVENESS SUPPORTED BY FEDERAL CONSTITUTION/88 IN PUBLIC POLITICS APPLICATION.}

\begin{abstract}
With the prediction of rights and guarantees, which today are conferred to each individual, in particular the fundamental social rights, enforced by the Federal Constitution / 88 , the present article comes in simplified way cover the historicity and the evolution of human relationships, facts that allowed the occurrence and extent of social progress over the years, including the application of public policies in Brazil. Showing however, the positive reflections of the currently existing social projects, not as a form of manipulation in the relationship between government and individual, but as a mandatory provision on the part of the democratic State of law . Finally, will be presented in general terms a social construction under the primacy of a dignified, just and egalitarian life.
\end{abstract}

Keywords: Democracy, human dignity, social progress, fundamental rights, public politics; 


\section{INTRODUÇÃO}

Diante da grande evolução das relações humanas e os fatores históricos que refletiram a níveis mundiais tornou-se necessário que o Estado também progredisse.

Para tanto, o surgimento do Estado Democrático de Direito trás consigo alguns alicerces primordiais em busca do bem comum, sendo um deles a guarda pela dignidade humana, ou seja, o dever de possibilitar e assegurar aos indivíduos uma vida digna e justa, analisando a sociedade em plano horizontal e igualitário.

A Constituição Federal/88 consagra em seu art. 6o os direitos fundamentais sociais, sendo estes: direito a moradia, a segurança, a educação, a saúde, ao lazer, a alimentação, a previdência social, a proteção à maternidade e à infância, e, a assistência aos desamparados.

Diante deste escopo, será demonstrado que o amparo constitucional efetivo a esses direitos geram uma prestação positiva por meio das políticas públicas, possuindo importantíssimo e essencial reflexo, tornando-se a base do progresso social.

\section{METODOLOGIA}

$\mathrm{Na}$ busca de apresentar o progresso social amparado pela Constituição Federal /88 em consonância aos direitos fundamentais sociais, este artigo está baseado em estudos bibliográficos e legislações afins, trazendo conclusões absorvidas através de pesquisas sobre o desenvolvimento histórico dos Direitos Humanos e também de Índices de Desenvolvimento social.

Para isto, será divido em duas partes, sendo a primeira delas, para versar da compreensão da Declaração Universal dos Direitos Humanos como um fator gerador de potência a este progresso no plano inicial, abrangendo as relações humanas e as necessidades da época.

$E$, em segundo momento, serão observadas as políticas públicas interpretando os projetos sociais como os instrumentos de realização da cidadania plena. Em especial, para sanar as diferenças e as desigualdades sociais com o anseio em possibilitar o progresso da sociedade.

\section{RESULTADOS}

O resultado alcançado através deste estudo baseia-se na observação crítica da eficácia das políticas públicas no Brasil, tendo como parâmetro os reflexos causados no próprio meio social em que vivemos e afastando o sensacionalismo midiático aos quais somos expostos diariamente ao que refere à inclusão social e aos projetos governamentais e sua eficácia.

Abrangeu-se o aspecto e a magnitude dos direitos consagrados na Constituição vigente, aos quais possuem uma carga histórica de grande valor e que, através da Declaração Universal dos Direitos Humanos, trata-se de direitos que refletem direta e obrigatoriamente no ordenamento jurídico dos países membros da Organização das Nações Unidas.

Tornou-se possível a reflexão sob a primazia pela dignidade da pessoa humana dentro de um Estado Democrático de Direito, em especial no Brasil, onde os direitos fundamentais sociais de cada indivíduo são efetivados por intermédio das politicas publicas.

Diante do estudo realizado, das análises de pesquisas a sensos demográficos divulgados pelos Indicadores do Instituto do Progresso Social - IPS do ano de 2014, depara-se com a realidade fática da sociedade brasileira, como também, com o empoderamento acarretado as áreas de maior abrangência ao qual se direcionam esses projetos sociais.

\section{DISCUSSÃO}

A Declaração Universal dos Direitos Humanos (DUDH), redigida sob o impacto dos horrores e violações de direitos vividos durante a Segunda Guerra Mundial, proclamada pela Assembleia Geral das Nações Unidas em Paris na data de 10 de dezembro de 1948, e, reiterada pela Declaração de Direitos Humanos de Viena em 1993, é considerada um dos mais importantes documentos para a efetivação dos direitos humanos, pois, além de produzida por representantes 
de diversas partes do mundo, determinou a proteção universal a esses direitos. Sendo que, nos dias atuais tal Declaração possui natureza jurídica vinculante.

Pode-se perceber que apenas a partir do pós-guerra, o problema da supressão dos direitos humanos passou a ser um problema de esfera internacional, envolvendo todos os povos e não se tratando mais de uma questão interna de cada Estado.

Como fruto do movimento de internacionalização de direitos humanos, fez-se necessário a criação de uma medida internacional para que a proteção de tais direitos fosse eficaz. Essa medida, se trata da Declaração anteriormente citada, que, de maneira abrangente, afirmou que "todos os homens nascem livres e iguais em dignidade e em direito", com a finalidade de promover e fazer-se reconhecer o aspecto universal dos direitos humanos.

A referida Declaração seria apenas a potência de uma primeira etapa que viria a se desdobrar em diversas fases, quais sejam: o desenvolvimento dos princípios nela elencados em acordos internacionais de conteúdos singulares, que de fato vieram a ser produzidos através de dois pactos aprovados pela Assembleia Geral das Nações Unidas, sendo estes: O Pacto de Direitos Civis e Políticos (os chamados Direitos da 1ạ geração) caracterizados pela ação negativa do Estado, e o de Direitos Econômicos, Sociais e Culturais (os chamados Direitos da 2a geração), marcados pela atuação positiva do Estado, haja vista a necessidade da atuação estatal para que tais direitos se concretizem. Isto posto, caracteriza-se a transição do Estado Liberal para o Estado Social.

Todavia, foi a partir do processo de democratização no Brasil, deflagrado em 1985, e em especial com o advindo da promulgação da Constituição Federal de 1988, que o Brasil passou a fazer parte da comunidade internacional de defesa dos direitos humanos, e, consequentemente vários tratados a respeito da matéria em questão, que já vigoravam no plano internacional e passaram então a vigorar no Brasil. Com a edição da Constituição vigente, os direitos humanos passaram a ocupar uma posição de extrema importância no ordenamento jurídico pátrio, elencados logo após a declaração dos princípios fundamentais, ao que chamamos de direitos fundamentais sociais.

Para uma melhor compreensão deste termo, vejamos o que leciona Alexandre de Moraes em seu Livro: Direito Constitucional, página 203, da 30ạ edição, ano de 2014:

"Direitos sociais são direitos fundamentais do homem, caracterizando-se como verdadeiras liberdades positivas, de observância obrigatória em um Estado Social de Direito, tendo por finalidade a melhoria de condições de vida aos hipossuficientes, visando à concretização da igualdade social, e são consagrados como fundamentos do Estado democrático (...)"

Conclui-se então, que os direitos sociais referem-se à aquilo que lhe é de fundamental do ser humano, um paradigma ao qual o Estado deve observá-lo e protegê-lo em caráter obrigatório.

A Constituição da República Federativa do Brasil, versa a respeito dos direitos humanos em seu artigo 6ㅇ, e dispõe que: "São direitos sociais a educação, a saúde, a alimentação, o trabalho, a moradia, o transporte, o lazer, a segurança, a previdência social, a proteção à maternidade e à infância, a assistência aos desamparados, na forma desta Constituição".

Sendo assim, o artigo de lei supracitado aborda a teoria do mínimo existencial, haja vista que, implicam no mínimo de garantias para que um indivíduo possa viver com dignidade, observância essa, a que se refere o próprio princípio basilar da Dignidade da Pessoa Humana, elencado no rol dos direitos fundamentais, como um valor inerente à pessoa. É importante ressaltar que a Constituição vigente é clara ao afirmar em seu artigo 5으, parágrafo 1ㅇ, que: "As normas definidoras dos direitos e garantias fundamentais tem aplicação imediata".

Dessa maneira, salienta-se que o conceito de direitos humanos é imbuído de universalidade, uma vez que possui extensão universal, e que basta possuir a condição de pessoa para ser titular desses direitos. A universalização desses ensejou a formação de um sistema 
internacional de proteção formado por tratados internacionais, desse modo, os Estados possuem obrigação legal de impulsionar e respeitar os direitos e liberdades fundamentais, não se restringindo apenas à sua jurisdição.

Porquanto, a Constituição Federal em seu art. 5o, parágrafo 2, dispõe que:"Os direitos e garantias expressas nessa Constituição não excluem outros decorrentes do regime e dos princípios por ela adotados, ou dos tratados internacionais em que a Republica Federativa do Brasil seja parte".

Dado o exposto, observa-se que a efetivação desses direitos constitucionalmente amparados serviu de base para um grande progresso da sociedade, essencialmente ao resguardar os direitos sociais previstos no artigo 60 , e, tendo em vista que os tratados internacionais relativos à proteção dos direitos humanos também possuem natureza de norma constitucional e aplicação imediata.

Mas, apenas por conter em nossa Constituição Federal/88 podemos concluir como atendidos e amparados os direitos fundamentais sociais de cada indivíduo? Como analisa-los?

Diante do primeiro questionamento a resposta certamente será negativa. $O$ fato é que, intrinsicamente, este amparo constitucional não surtiria tantos efeitos positivos se apenas abrangesse essa esfera teórica, tornando-se necessário, efetivar-se também uma responsabilidade prática do Estado frente a fornecer uma vida digna ao individuo e agir de maneira sólida para a busca do bem comum.

Ao que consta a segunda indagação, em atendimento a esta necessidade de amparo técnico na relação Estado-indivíduo diante dos direitos sociais, temos o que chamamos de políticas públicas, ou seja, os projetos sociais de ordem pública que visam solucionar os problemas da sociedade de maneira coletiva em busca da igualdade e o alcance de cidadania plena.

Muito embora, certos da importância e objetivo primordial das politicas publicas, podemos indagar como se constitui sua essência e como esta é delimitada. Para isto, vejamos o que apresenta (DIAS, MATOS, 2012, p.69)

“Delimitar um problema público é politicamente fundamental no processo de elaboração de uma política pública; envolve definir quais são seus elementos e sintetizar em uma fase a essência do mesmo. No entanto, é importante destacar que qualquer definição oficial do problema é temporária. Nas fases sucessivas de formulação das alternativas e, principalmente, na implementação, os problemas públicos podem ser redefinidos e adaptados por alguns doa atores envolvidos." (DIAS, MATOS, 2012, p. 69).

Ante o exposto, verifica-se que os projetos sociais: instrumentos de aplicabilidade das políticas públicas, ao serem projetos percorrem alguns requisitos, sendo estes: a) a delimitação do problema público, e, b) a área de abrangência à determinado projeto.

Atualmente, diversos são esses projetos, como exemplo verifica-se: Bolsa Família, Cotas nas Universidades, Bolsa Escola, Brasil Alfabetizado, Fundo de Amparo ao Trabalhador, Bolsa Atleta, Auxilio Gás, entre outros.

Muito além de uma visão rasa e leiga ao que sobrepõe estes projetos como meras fontes de manipulação entre governo e indivíduo, somos levados a analisá-los como uma prestação obrigacional desta ordem.

Ao que se finda o objetivo final destes projetos que efetivam os direitos sociais?

As políticas públicas garantem ao individuo sua inclusão na sociedade, trazendo um empoderamento protegido pelo próprio poder estatal. De fato, nos últimos anos, positivamente, estes projetos viabilizaram uma grande inclusão social, sanando dentro do possível as diferenças de classes, de cor, de sexo, de religião, etc. Esta inclusão acrescida no Estado trás consigo a 
miscigenação de raças e ampliação de oportunidades de empregos, estudos e fornecimentos de subsídios e proteções básica aos direitos sociais do indivíduo.

Em pesquisa obtém-se que os dados sintéticos divulgados pelo Instituto do Progresso Social fornecidos no site da Editora Carta Maior, no ano de 2014 apontam o Brasil como 46응 colocado no ranking mundial, observando o satisfatório índice de desenvolvimento ao que relaciona os fundamentos do bem- estar, o atendimento as necessidades básicas e as oportunidades oferecidas.

Analisando por este prisma, torna-se visível a democracia em termos de igualdade mediante as formas de inclusões existentes em nosso país, obtendo como fonte a realização governamental efetivada nas políticas públicas. O Estado Constitucional, sendo democrático e de direito, deve zelar pela igualdade plena e possibilitar o progresso social.

O que podemos concluir com a divulgação positiva deste senso demográfico de fundamentos do bem-estar para o nosso país?

Amplamente, interpretando esses projetos torna-se visível seu objetivo principal: a inclusão social e favorecimento da classe hipossuficiente. Como por exemplo: as cotas nas universidades; tem-se por finalidade a convivência das diferenças raciais vendo-as no plano horizontal, já o programa bolsa família; busca fornecer ao individuo até mesmo bolsas de estudo quando estes se dedicam voluntariamente em trabalhar no projeto, com o fim maior de proporcionara população abrangente uma interatividade, inclusão e lazer. Porquanto, o fundo de amparo, bolsa atleta, vale leite, auxílio gás, entre outros, buscam fornecer subsídios básicos às famílias carentes.

Diante desta análise simplificada, podemos então, concluir os programas sociais como instrumentos de caráter essencial e indispensável para a busca do bem comum. Ainda que pouco observado e não assim concluído pela maioria sociedade, são projetos de grande importância à aqueles que precisam.

Com tudo, somos possibilitados a compreender pela efetividade dos direitos fundamentais sociais constitucionalmente amparados e completados em sua aplicabilidade prática na imperatividade das politicas publicas no Brasil possuindo caráter inescusável nas relações sociais.

\section{CONCLUSÃO}

A partir do estudo realizado se depara com a importância das políticas públicas no Brasil nas quais são instrumentos de aplicabilidade dos direitos fundamentais sociais.

Em análise aos reflexos desses projetos e com base em pesquisas de índices de desenvolvimento e progresso, nota-se a essencialidade deste ato do poder publico de maneira positiva e o atingimento às classes necessitadas.

Ao estudar a história dos direitos humanos, conclui-se pela suma contribuição do período pós-guerra em que se redigiu pela ONU a Declaração Universal dos Direitos Humanos, impondo aos países membros ao qual o Brasil compõe, e também, do surgimento do Estado Democrático de Direito, uma observância obrigatória à dignidade humana dentro do óbice jurídico.

Muito embora, resta a certeza de que ainda há muito a se expandir e aperfeiçoar nos projetos sociais de inclusão e empoderamento das classes hipossuficientes, verificados pelos benefícios acarretados diante da efetivação das políticas públicas, sendo estes, já reconhecidos e apresentados nos índices demográficos de pesquisas realizadas à nível mundial.

Torna-se tamanha a importância para nosso país, território tão repleto de diversidades, a evolução já obtida pela efetivação e proteção dos direitos fundamentais sociais na Constituição/88.

No entanto, caberá ao governo a continuidade desses projetos e a busca, cada vez mais, ao bem comum e ao progresso social convergente na dignidade da pessoa humana e na efetivação das políticas públicas como meio de combater as desigualdades sociais em nosso país. 


\section{REFERENCIAS}

BRASIL. Constituição. Constituição Federal. Brasília: Senado Federal, 1988.

DALARI, Dalmo de Abreu. Teoria Geral do Estado. 33a edição. 2016.SARAIVA

MORAES, Alexandre. Curso de Direito Constitucional, 30ạ edição, Editora Atlas S.A, São Paulo, 2014.

TAVARES. André Ramos. Curso de Direito Constitucional. 3o ed. Ed. Saraiva,São Paulo: 2006.

VICENTE PAULO, Marcelo Alexandrino. Direito Constitucional Descomplicado, 8. Ed. Rio de Janeiro, Forense; São Paulo: MÉTODO: 2012.

http://www.egov.ufsc.br/portal/conteudo/efetiva\%C3\%A7\%C3\%A3o-dos-direitos-sociaisatrav\%C3\%A9s-das-politicas-p\%C3\%BAblicas

http://www.ambitojuridico.com.br/site/?n_link=revista_artigos_leitura\&artigo_id=9650\&revista_ caderno=9http://www.portalconscienciapolitica.com.br/ci\%C3\%AAnciapolitica/politicas-publicas/

http://www.cartamaior.com.br/?/Editoria/Economia/Indicadores-de-Progresso-Social-Brasil-commais-forte-progresso-social/7/30695

http://www.ufjf.br/eticaefilosofia/files/2009/08/16_1_benedito.pdf 